\title{
Effects of Eccentric Strength Training's Duration on Daily Plasma Testosterone Levels in Tunisian Male Sedentary Athletes
}

\author{
Salah Souissi ${ }^{1}$, Sabri Gaied Chortane ${ }^{1}$, Maamer Slimani ${ }^{2}$, Rachid Sakli $^{3}$ \\ and Foued Chéour ${ }^{4}$ \\ ${ }^{1}$ High Institute of Sport and Physical Education of Sfax, Tunisia \\ ${ }^{2}$ Faculty of Sciences of Bizerte, Tunisia \\ ${ }^{3}$ Ecole Supérieure des Sciences et Techniques de la Santé de Monastir, Tunisia \\ ${ }^{4}$ Thesis supervisor, High Institute of Applied Biology of Médenine, Tunisia
}

\begin{abstract}
This study aims to evaluate the effects of the eccentric strength training's duration on daily plasma testosterone concentrations in Tunisian male sedentary athletes. Ninety male athletes, with homogeneous age $(21.23 \pm 0.83$ years $)$, height $(1.75 \pm 0.14)$ and weight $(72 \pm 1.52 \mathrm{~kg})$ were selected for the study during three months. They were subjected to a strength training of the knee extensor and flexor muscles. After, they were divided into three groups of thirty subjects and then had eccentric strength training either in the morning between 6 and 7, in the evening between 16 and 17 or successively in the morning and in the evening at the hours mentioned. The dosage of testosterone on each athlete was performed before and after submission to an eccentric strength program at the antecubital vein in a restful sitting. Our results have shown that eccentric strength training induces the increase of this androgen in the two groups of athletes who have always trained for only one session per day in the morning or in the evening, and the training in the evening promotes better its production. However, a reduction of the testosterone's production was observed in the athletes group who has always trained successively in the morning and in the evening. We conclude that depletion of athletes during daily eccentric strength training reduces the testosterone production. On the other hand, moderate exercises do that to increase the synthesis in the latter.
\end{abstract}

Keywords: testosterone levels; training duration; eccentric strength training.

\section{Introduction}

Recent studies reported that the eccentric strength training's time, mainly in the afternoon, greatly influences the production of testosterone in athletes (Sedliak et al., 2007; Yildirim and Derksen, 2012; Souissi et al., 2013). However, it did not specify the effects of the duration on the synthesis of this hormone. Testosterone, anabolic hormone, has action characteristics and quite specific metabolic effects. It is an anabolic androgenic hormone. It is secreted mainly by the testes and plays an important role in growth, development and maturation of the male skeletal system. It also contributes to skeletal muscle growth and to the development of strength (Bhasin et al., 2001, Crewther et al., 2012; Souissi et al., 2013). At rest and during physical exercise, hormonal system intervenes in the metabolism of carbohydrates, fats and proteins. Testosterone has a specific role in all of these functions, and depending upon the duration and intensity of exercise, its plasma concentration changes (Kraemer et al., 2005). This endocrine adaptation is essential for muscle regulation. Its action, like other steroids, is also closely dependent on the quality of a binding to a receptor protein present in the nucleus of target cells (Singh et al., 2012). The objective of this study was to evaluate the effects of eccentric strength training's duration in sedentary athletes on the daily changes in plasma testosterone levels.

\section{Materials and methods}

Ninety Tunisian male volunteers' athletes have been carefully selected to participate in the study. Their average's age, height and weight were respectively ordered as following: $21.23 \pm 0.83$ years, $1.75 \pm 0.14 \mathrm{~m}$ and $72 \pm 1.52 \mathrm{~kg}$. The participants were divided into three groups of thirty athletes. The first group has always been testing strength in the morning's hours between 7 and 8 , the second one was starting at the afternoon hours between 16 and 17 and the third sparred simultaneously with the first and the second group. Throughout the periods of training, the athletes followed a strict hygiene and similar life.

Training plan recommended in this study was reported by Souissi et al. (2013). The selected athletes for our study have concentric and eccentric strength training respectively during 4 and 8 weeks. They have a strength training of the knee extensor and flexor muscles with three sessions per week. Two successive sessions were separated by at least 48 hours. Three units of the gym of the Higher Institute of Sport and Physical Education of Sfax, Tunisia, namely 'Leg Extension', the 'Leg Curl' and 'Squat' were used. The training program was preceded by determining the maximum repetition (RM-1) at each unit. The 1-RM was adjusted after every 
four weeks of training. During the first four weeks of training, light loads (60 and 70\% 1-RM), and the mode of concentric contraction, were imposed to prepare participants for the eccentric drive. For last weeks, the training was based on eccentric contractions with heavy loads (100, 110 and $120 \%$ of 1-RM).Thus the athletes curb without blocking the movement resulted by the training charge during the downswing phase at each unit. Every athlete has only one session's test daily with a rest of 24 hours.

The dosage of testosterone in each athlete was always done before and after submission to eccentric training program at the antecubital vein in a restful sitting position. Each blood's sample was frozen at $-70^{\circ} \mathrm{C}$ before biochemical analysis. The Plasma testosterone concentrations were determined in the laboratory of biochemistry at the University Hospital's center of Habib Bourguiba, Sfax by ELISA (Enzyme Linked Immuno Sorbent-Assay) according to the method described by Singh et al. (2011). The normal range was calibrated and then $25 \mu \mathrm{l}$ serum samples were taken in the well plates. $100 \mu \mathrm{l}$ of enzyme conjugate was added in each well. After that, it was left for incubation at $37^{\circ} \mathrm{C}$ in incubator for 1 hour. Then, the wells were washed with $300 \mu 1$

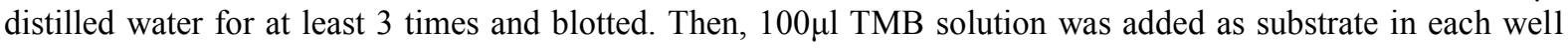
plate and was again left for the incubation for 15 minutes for the color. Finally, $100 \mu \mathrm{l}$ stop solution was added in each well to stop the reaction. Reading was taken at $630 \mathrm{~nm}$ through Merck ELISA reader in $\mathrm{ng} / \mathrm{ml}$ value.

The analysis of variance (ANOVA) of results was made following a randomly complete block design (Snedecor and Cochran, 1957) by the GLM procedure of the SAS statistical package (SAS Institute, 1989). Homogeneity of variance was verified by the standard Bartlett test (Anderson and McLean, 1974).

\section{Results}

The mean values of plasma testosterone levels measured in the morning, afternoon and evening before and after eccentric training in Tunisian male sedentary athletes are presented in figures 1,2 and 3.

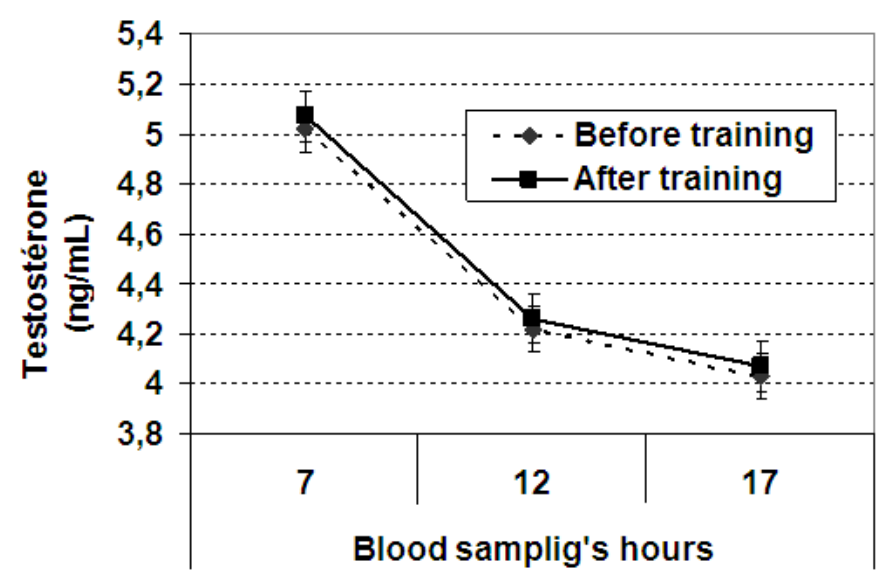

Figure 1. Daily evolution of plasma testosterone levels in Tunisian male sedentary athletes before and after submission to eccentric strength training in the morning. Vertical bar shows average \pm SD for 30 athletes.

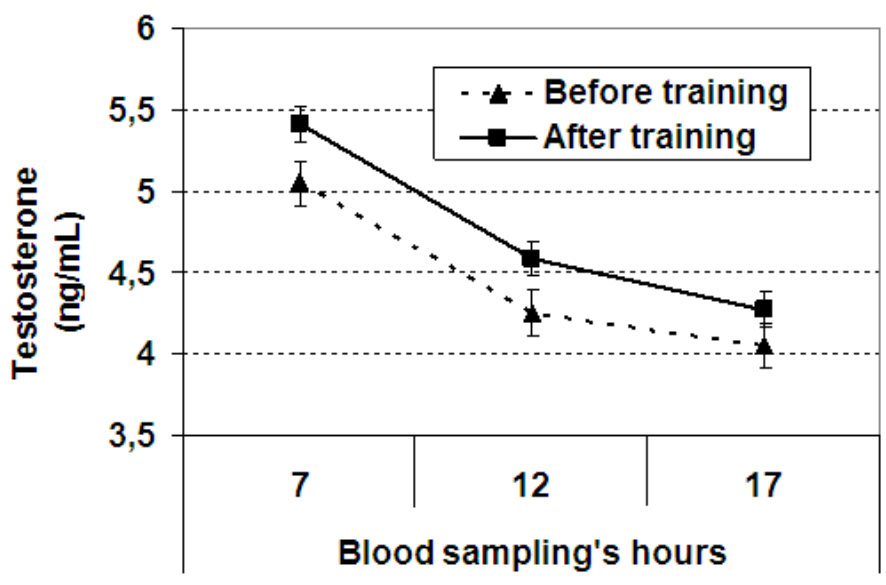

Figure 2. Daily evolution of plasma testosterone levels in Tunisian male sedentary athletes before and after submission to eccentric strength training in the evening. Vertical bar shows average \pm SD for 30 athletes. 


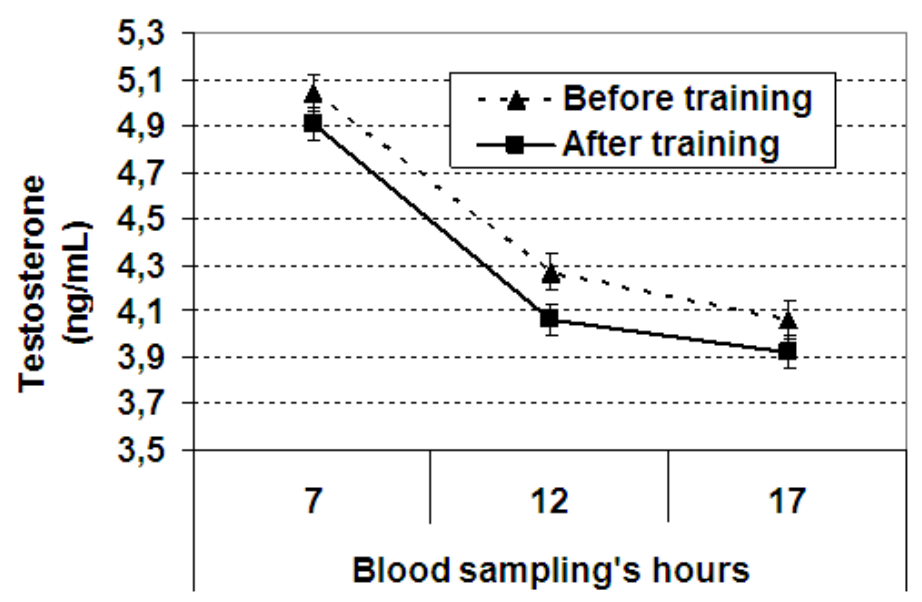

Figure 3. Daily evolution of plasma testosterone levels in Tunisian male sedentary athletes before and after submission to eccentric strength training in the morning and in the evening. Vertical bar show average \pm SD for 30 athletes.

The submission to eccentric strength training of the Tunisian male sedentary athletes in the morning or in the evening for three months induced an increase in plasma testosterone levels compared with respective controls (Figures 1 and 2). This increase was significant only for the group of subjects who were still subjected to eccentric strength training in the evening $(\operatorname{Pr} \leq 0.01)$. Nevertheless, inverse effects were observed in athletes who were subjected to the same eccentric strength training successively in the morning and in the evening during the same period. Indeed, the production of this androgenic anabolic steroid decreased later significantly compared with placebo (Figure 3).

Plasma testosterone levels were significantly decreased during the day for trained athletes either in the morning, in the evening or successively in the morning and in the evening as well as for their respective controls $(\operatorname{Pr} \leq 0.001)$ (Figures 1, 2, 3). Nevertheless, a diminution of hormone levels was more pronounced in the athletes who were still subjected to eccentric strength training successively in the morning and in the evening $\operatorname{Pr} \leq$ $0.001)$.

\section{Discussion}

The realisation of a physical exercise requires adjustment of many dependent functions such as the duration, intensity, frequency and the specific characteristics of sport practiced. The neuroendocrinien regulation is one of these functions for adjustment of hormonal secretions and the involvement of appropriate energy processes (Duclos, 2001; Baris et al., 2012; Yildirim and Derksen, 2012).

Our study showed that the submission of Tunisian male sedentary athletes to eccentric strength training during eight weeks either in the morning, in the evening or successively in the morning and in the evening at the rate of one hour per session influences significantly the baseline testosterone levels. In fact, with only one training per day either in the morning or in the evening, daily concentrations of this hormone increase in athletes. This increase is the result of a reduction in plasma volume with hemoconcentration and increased blood viscosity on the one hand, and a rise in testicular perfusion on the other hand as it was reported by Souissi et al. (2013). However, by imposing two training sessions daily to athletes, successively in the morning and in the evening, which probably led to depletion, a decrease in daily production of this androgen was observed. The hypotestosteronism installation following the exhaustion of marathon runners has been reported by Dessypris $e t$ al. (1976) and Pesquiès et al. (1991). The latter could be concomitant with the reduction of muscle and liver glycogen reserves, on the one hand, and in the insulin decline on other hand (Elias et al., 2011; Cook et al., 2013) These authors showed that during a long-term effort, there is a decrease in plasma levels of luteinizing hormone $(\mathrm{LH})$, and an increased secretion in the pendorphines proving the existence of a stress related to muscle activity.

By feedback dissociation of LH, the hypotestosteronism install gradually as the exercise continues. The physiological role of this decrease in plasma testosterone concentration is an adaptive phenomenon, which should be respected, as it helps to remove an inhibitory brake on glycogenolysis, and otherwise facilitating proteolysis to supply the gluconeogenesis in amino acids like the alanine (Bricout, 2000; Kvorning et al., 2006). Moreover, the myotropic action of endogenous androgens opposes to the catabolic action of proteins degradation of muscle, in which cortisol is responsible, and without it the muscle atrophy would quickly place during intense physical repeated effort (Callard et al., 2000; Hayes et al., 2010). Moreover, during recovery, the balance between cortisol and testosterone remains between 48 and 72 hours to facilitate the replenishment of 
glycogen both in muscle and liver levels, and must be seriously respected the resting phase to chain workloads satisfactory (Duclos, 2001; Hayes et al., 2010; Crewther et al., 2012).

In conclusion, this study showed that the eccentric strength training's duration influences significantly the synthesis of testosterone in Tunisian male sedentary athletes. Daily workouts of short-lived in the morning or in the evening merely promote its production. However, depletion of athletes does give opposite results.

\section{References}

[1]. Anderson VL., McLean RL. 1974. Design of experiments. Marcel Dekker, New York.

[2]. Baris O., Yildirim AN., Jan JL., Derksen B. 2012. A review on the relationship between testosterone and life-course persistent antisocial behaviour. Psych. Res., 200, 984-1010.

[3]. Bhasin S., Woodhouse L., Storer TW. 2001. Proof of the effect of testosterone on skeletal muscle. J. Endocrin., 1701, 27-38.

[4]. Bricout VA. 2000. Mode d'action et effets physiologiques de la testostérone ou de l'inutilité d'un apport d'anabolisants chez le sportif. Sci. Sport. 15, 3-9.

[5]. Bird SP., Tarpenning KM. 2004. Influence of circadian time structure on acute hormonal responses to a single bout of heavyresistance exercise in weight-trained men. Chronobiol. Int., 21, 131-46.

[6]. Callard D., Davenne D., Gauthier A., Lagarde D., Van Hoeke J. 2000. Circadian rhythms in human muscular efficiency: Continuous physical exercise versus continuous rest. A crossover study. Chronobiol. Int., 17, 693-704.

[7]. Cook CJ., Liam P., Kilduff LP., Crewtherc BT., Beavenf M., Westb DJ. 2014. Morning based strength training improves afternoon physical performance in rugby union players. J. Sci. Med. in Sport. (in press).

[8]. Crewther BT., Kilduff LP., Cook CJ. 2012. Relationships between salivary free testos-terone and the expression of force and power in elite athletes. J. Sports Med. Phys. Fitness. 52, 221-227.

[9]. Dessypris A., Kuoppasalmi K., Aldercreutz H. 1976. Plasma cortisol, testosterone, androstenedione and luteinizing hormone (LH) in a noncompetitive marathon run. J Steroid Biochem., 7, 33-7.

[10]. Duclos M. 2001. Effets de l'entraînement physique sur les fonctions endocrines. Ann. Endocr., 62, 19-32.

[11]. Hayes LD., Bickerstaff GF., Baker JS. 2010. Interactions of cortisol, testosterone, and resistance training: influence of circadian rhythms. Chronobiol Int., 27, 675-705.

[12]. Kraemer WJ., Ratamess NA. 2005. Hormonal responses and adaptations to resistance exercise and training. Sports Med., 35, 339361 .

[13]. Kvorning T., Bagger M., Caserotti P., Madsen K. 2006. Effects of vibration and resistance training on neuromuscular and hormonal measures. Eur. J. Appl. Physiol., 96, 615-625.

[14]. Pesquies PC., Guezennec CY., Serrurier BD., Guignard M. 1991. Plasma ... ACTH, and cortisol during prolonged physical exercise. J. Appl. Physiol., 71, 1807-12.

[15]. Sedliak M., Finni T., Cheng S., Kraemer WJ., Häkkinen K. 2007. Effect of time-of-day-specific strength training on serum hormone concentrations and isometric strength in men. Chronobiol. Int., 24, 1159-1177

[16]. SAS Institute, 1989. SAS/STAT User's Guide, ver. 6, vol. 2, 4th ed. SAS Institute, Cary, N.C.

[17]. Snedecor GW., Cochran WG. 1957. Statistical Methods. 6th ed. Iowa State Univ Press.

[18]. Singh JK., Nath A., Kumar A., Md. Ali M., Kumar R. 2011. Study on the effect of endosulfan on testosterone level and seminiferous tubule of testis of mice. World J. Envir. Poll., 1, 1-4.

[19]. Souissi S., Chéour F. 2013. Effects of eccentric strength training's time on daily plasma testosterone levels among Tunisian sedentary athletes. IOSR J. Pharmacy Biol. Sci., 2, 69-72.

[20]. Yildirim BO., Derksen JL. 2012. A review on the relationship between testosterone and life-course persistent antisocial. Psych. Res., 200, 984-2010. 